\title{
As cotas fazem diferença? Ações positivas no parlamento Belga
}

\author{
Mercedes Mateo Diaz \\ Universidade Católica de Lovaina
}

\begin{abstract}
Resumo
A Bélgica tem a peculiaridade de ser o único Estado-membro da UE a ter introduzido cotas em sua legislação. 0 tipo de cota que foi implementada prioriza o número, sem dar atenção a como candidatos masculinos e femininos estão posicionados nas listas dos partidos. Neste artigo, a autora examina a evolução do número de mulheres no Parlamento belga ao longo do tempo. Fazem-se comparações dentro dos partidos e entre eles, antes e depois da lei sobre cotas. A análise mostra que, em larga medida, o efeito das cotas depende da vontade dos partidos de obter mais representantes do sexo feminino. Assim, se o principal objetivo de uma legislação sobre cotas é impor uma estrutura de gênero equilibrada na assembléia de representantes, a legislação precisa considerar as posições dos homens e das mulheres nas listas.
\end{abstract}

Palavras-chave: candidatos, cotas, listas partidárias, Parlamento belga, representação

\section{Abstract}

Belgium has the particularity of being the only EU Member State to have introduced quotas to its legislation. The type of quota which has been implemented is prioritizing the number, without paying attention to how male and female candidates are positioned on the parties' lists. In the article the author examines the evolution of the number of women in Belgian Parliament across time. Comparisons are made within and between parties, before and after the law about quotas. The analysis shows that the effect of quotas to a large degree is dependent on the will of parties to obtain more female representatives. Thus, if the major aim of a legislation on quotas is to impose a balanced gender structure in the representatives' assembly, the legislation ought to consider men's and women's positions on the lists.

Key words: candidates, quotas, party lists, Belgium Parliament, representation 


\section{Introdução*}

Uma análise superficial do aumento do número de mulheres no Parlamento belga concluiria que isso se deve à nova política de cotas, posta em prática durante as eleições de 13 de junho de $1999^{1}$. Porém, como acontece com freqüência nas ciências sociais, correlação não implica causalidade. Este artigo mostra que o aumento não foi causado pela nova legislação sobre cotas, mas pelo fato de que o eleitorado escolheu votar em partidos que tinham mais mulheres em posições elegíveis e "de briga" (isto é, logo após as posições elegíveis)².

Este artigo discute brevemente os aspectos positivos e negativos relacionados com medidas desse tipo. Porém, seu objetivo é estudar o efeito das cotas em termos de equilíbrio entre os sexos e, em especial, o tipo de cota usado na eleição belga de 1999. Esse tipo de cota dá prioridade a números, e não à posição nas listas. Quais são os limites para cotas desse tipo? Em que medida o aumento ou a diminuição na proporção de membros do sexo feminino está relacionado com a verdadeira vontade dos partidos e dos eleitores, a fim de ter mais representantes mulheres, ou ele reflete apenas a eficácia do próprio mecanismo?

O artigo está estruturado em cinco partes. A primeira trata do debate teórico sobre a implementação das cotas e outras ações positivas, bem como de seu impacto sobre a natureza da representação. Na segunda seção, examina-se a opinião do eleitorado sobre a igualdade política entre homens e mulheres. Os resultados empíricos dessa parte do estudo levam a discussão a uma outra direção: há um hiato entre a oferta dos partidos e a demanda dos eleitores? Na terceira parte, são abordados alguns traços fundamentais da evolução e da situação atual do status político das mulheres na Bélgica. Na quarta seção, descrevem-se as ações positivas empreendidas pelos partidos políticos belgas. Por fim, a quinta e última seção mostra os efeitos da lei Smet-Tobback (legislação sobre cotas) sobre a

\footnotetext{
* Gostaria de agradecer a Hans E. Anderson, Ann Carton, Lieven De Winter, ao seminário VOD (Departamento de Ciência Política da Universidade de Göteborg) e aos leitores anônimos por seus comentários a uma versão anterior deste artigo. Sou também grata aos dois partidos socialistas (SP e PS), ao Partido Liberal Flamengo (VDL), ao Partido Democrata-Cristão Flamengo (CVP), ao partido regionalista Flamengo (VU), ao Partido Verde Francófono (Ecolo) e ao partido de extrema direita flamengo (Vlamms Blok) por me fornecerem as listas de candidatos necessárias para este artigo. $\mathrm{O}$ resto foi completado com dados do Ministério do Interior belga (Departamento de Eleições). Por fim, gostaria de expressar minha gratidão à rede TMR "Representação na Europa" por seu apoio financeiro e por ser um ambiente estimulante para jovens pesquisadores.

${ }^{1} 13$ de junho de 1999 não foi apenas o dia em que a Bélgica realizou eleições nacionais, regionais e européias, mas também a primeira vez em que uma legislação sobre cotas foi implementada em um dos quinze Estados-membros da UE. Há outros cinco países em todo o mundo que introduziram cotas em sua legislação eleitoral: Argentina, Brasil, Nepal, Filipinas e República Democrática da Coréia. No que se refere à UE, a França optou pelo conceito de paridade representativa entre homens e mulheres.

${ }^{2} \mathrm{O}$ sistema eleitoral belga permite que se escolha pessoas específicas dentro das listas dos partidos. A posição dos candidatos dentro das listas dos partidos determina a probabilidade de elegibilidade.
} 
distribuição sexual na Câmara Federal de Deputados da Bélgica³.

\section{A base teórica para utilizar cotas}

Um dos tópicos recorrentes na literatura das últimas décadas é a questão da sobre-representação de certos grupos e a sub-representação de outros. Bernard Manin chamou a isso de “o caráter aristocrático da representação" (Manin, 1995). No Manifesto pela paridade francês, impresso um ano depois da publicação do livro de Manin, "o caráter aristocrático da representação" é descrito da seguinte forma:

"As funções representativas e executivas são monopolizadas por um grupo dirigente, pequeno em número, extremamente homogêneo por seu treinamento e com uma inserção antiga nos principais organismos do Estado. Estável por sua composição e pouco permeável em seu acesso, esse grupo dirigente constitui uma "aristocracia democrática" sob o disfarce de uma elite republicana"4.

Essa situação de desequilíbrio foi também chamada de "preconceito social do Parlamento".

Por que é importante para diferentes grupos serem representados de acordo com sua quantidade na sociedade como um todo? As respostas a essa questão parecem cair em duas amplas categorias. A primeira afirma que é uma questão de direitos, isto é, a democracia supõe igualdade (isto é, "uma mulher/ um voto" e "todo cidadão tem o mesmo direito de ser eleito") e portanto, o direito a uma representação social igual é um direito básico. A segunda baseia-se em argumentos mais utilitários, ou seja, a fim de se beneficiar da competência das mulheres, essa metade da humanidade deve fazer parte do sistema político. Ademais, a entrada de novos atores (no caso, as mulheres) na arena política mudará e aperfeiçoará a política, causando uma "renovação política". Isso não significaria apenas a entrada de novas questões e prioridades na agenda política, mas também traria a política e os políticos para mais perto do povo.

Pippa Norris e Joni Lovenduski (1995) usam um modelo de oferta e demanda para explicar porque os parlamentos permanecem "não-representativos" de acordo com vários critérios, tais como ocupação, educação, sexo, raça e idade. O modelo distingue dois tipos diferentes de fatores: aqueles que evitam a entrada de certos indivíduos no processo de recrutamento e aqueles que impedem os tomadores de decisões de escolher um tipo particular de indivíduo. Dois tipos de atitudes são uma desvantagem para certos candidatos e ajudam assim a reproduzir "preconceitos sociais". Em primeiro lugar, uma discriminação direta, definida como

\footnotetext{
${ }^{3}$ A Câmara de Deputados foi escolhida para análise porque é a assembléia legislativa federal mais forte. O Parlamento Federal belga é composto por duas casas: a Câmara de Deputados e o Senado. Porém, é um sistema assimétrico, em que a distribuição de competências favorece fortemente a Câmara. O foco sobre ela possibilita uma análise em nível nacional, juntamente com comparações dentro e entre os partidos francófonos e flamengos.

4 "Le Manifeste des dix pour la parité", L'Express, 6 de junho de 1996.
} 
“julgamento positivo ou negativo de indivíduos com base em supostas características do grupo ao qual pertencem, em vez de com base em suas próprias características individuais". E em segundo lugar, uma discriminação imputada, que pode ser descrita como "a reação antecipada do eleitorado com relação a certos grupos sociais" 5 .

Um sistema baseado na representação social requer que as assembléias reflitam a composição social. David Held chama a isso de "representação estatística", ou o método de eleição em que os representantes são uma amostra do grupo como um todo, escolhidos entre "aqueles que são estatisticamente representativos de categorias sociais fundamentais, entre elas, gênero e raça" (Held, 1997, p.325). Porém, os argumentos que consideram a proporcionalidade social um indicador do grau de eqüidade de um sistema político são controversos. Se um sistema é considerado injusto porque as mulheres são minoria no Parlamento, embora componham $50 \%$ da população, o mesmo poderia ser dito sobre outros grupos fisicamente distintos, tais como etnia ou idade. A linha de discussão passou, então do problema da questão de "por que é necessário ter assembléias representativas e igualdade política" para o problema mais específico de "por que se deveria introduzir uma igualdade política de gênero?" Um dos principais argumentos desse último debate tem sido o seguinte: uma vez que todas as sociedades sempre tiveram o gênero como componente essencial, essa questão é diferente das demais.

Várias ações, temporárias e definitivas foram criadas e aplicadas por partidos e parlamentos com a intenção de obter uma assembléia legislativa equilibrada em termos de sexo. Porém, é também essencial apontar as diferenças conceituais entre as "cotas" belgas e a "paridade" francesa quando se discute esse tema. À distância, esses dois conceitos poderiam ser vistos como semelhantes, isto é, medidas temporárias de correção, com o objetivo de alcançar um equilíbrio político entre homens e mulheres. No entanto, a paridade francesa é considerada uma medida definitiva que vai além dos aspectos quantitativos.

Mais do que serem simples ações, necessárias para obter a igualdade política entre homens e mulheres, cada um dos dois conceitos - cota e paridade representa uma visão particular da sociedade. Enquanto o primeiro vê a sociedade como organizada em grupos com interesses bem definidos, a idéia que está por trás do segundo é que a política tem de espelhar a dualidade da humanidade. O conceito de démocracie paritaire estipula que o poder político deve ser compartilhado "meio a meio" entre homens e mulheres. Aprovado e inserido na Constituição francesa, seus críticos ressaltam que o quadro conceitual de mixité

\footnotetext{
5 "Os membros do partido podem favorecer pessoalmente uma certa categoria de candidato [...], ou um determinado candidato [...]. Mas os membros podem não estar dispostos a escolher tal candidato porque imaginam que vão perder votos do eleitorado." (Norris e Lovenduski, 1995, p.107).
} 
disfarçou uma cota de "50-50". Porém, o fato de o gênero ser considerado um componente essencial de todas as sociedades evita que outros grupos sociais pleiteiem uma lei similar, diferente do que aconteceria no sistema de cotas. Mesmo que se diga que a base conceitual e filosófica dos dois conceitos é diferente, não é possível distinguir entre as duas posições quando se trata de sua implementação prática.

Apesar de provocar inúmeros debates na Bélgica, o princípio das cotas foi considerado um modo "natural" de obter uma representação equilibrada quanto ao sexo. Isso deveu-se à tradição do país de permitir que diferentes grupos compartilhem o poder. Portanto, como sustentam Eliane Gubin e Leen Van Molle (1998), quando a démocracie paritaire se tornou a prioridade política dos anos noventa, as medidas para obter um equilíbrio político entre os sexos não puderam ser postergadas. Parecia natural garantir representação igual a homens e mulheres, da mesma forma que foi tradicionalmente feito com grupos lingüísticos diferentes.

\section{Um eleitorado com opinióes positivas sobre igualdade de gênero}

Embora o principal objetivo deste artigo seja apresentar os efeitos da lei sobre cotas na Câmara de Deputados da Bélgica e ilustrar as variações em representatividade, está claro que as cotas são apenas um dos fatores, entre outros, que podem influenciar o processo de seleção de candidatos e deputados. Em um sistema político fortemente dominado pelo papel dos partidos políticos, os mecanismos de recrutamento dentro de cada um deles não devem ser negligenciados ${ }^{6}$. Às vezes, os processos democráticos - por exemplo, eleições no interior dos partidos - não são bem sucedidos em dar mais presença nas listas aos atores novos e sub-representados. Ao contrário, o sistema oligárquico - isto é, a tomada de decisões pela elite do partido, ou processos de cima para baixo - pode ser mais eficaz. Outro componente importante é a força e o impacto das seções de mulheres no interior dos diferentes partidos políticos, na medida em que elas têm estimulado com freqüência reformas no sentido da igualdade dos gêneros.

Porém, mesmo em um sistema dominado por partidos, o eleitorado tem participação ativa, especialmente em relação à preferência dos votos. Em última instância, são os eleitores, e não os partidos, que decidem por qual candidato querem ser representados. Neste sentido, não basta, ter um Parlamento equilibrado quanto ao gênero para forçar os partidos a apresentarem listas sexualmente equilibradas; os eleitores também têm de votar tanto em homens como em mulheres.

Diferentes campanhas promoveram o voto em mulheres junto a todo o

\footnotetext{
${ }^{6}$ Para uma análise do processo de recrutamento, ver Norris e Lovenduski, 1995.
} 
eleitorado. Em 1988, antes das eleições locais, Miet Smet desencadeou a campanha "Vote pelo equilíbrio em seu conselho comunal" (Votez pour l'équilibre dans votre conseil communal) ${ }^{7}$. Em 1994, organizou-se uma nova campanha para as eleições locais e provinciais, sob o slogan “E se mudássemos a face da política belga (Et si on changeait le visage de la politique belge). Para as eleições de 1995, a campanha "Vote por um equilíbrio entre as mulheres e os homens" (Votez pour un équilibre entre les femmes et les hommes) foi lançada com o apoio das autoridades, dos partidos femininos e de organizações não-partidárias. O Estudo Eleitoral Belga ${ }^{8}$ realizado em 1995 sustenta que mais homens (38\%) do que mulheres (28\%) ouviram falar da campanha. Assim, somente um terço (cerca de 33\%) de todos os entrevistados sabiam dela; o nível de consciência era mais alto em Flandres (38\%) do que na Valônia (28\%).

Conhecer uma campanha e ser influenciado por ela são duas coisas diferentes. Dos eleitores que ouviram falar da campanha, 16\% admitiram que seu voto foi influenciado por ela. De acordo com as respostas dos entrevistados, as mulheres (25\%) foram duas vezes mais influenciadas do que os homens (10\%). O impacto também parece ter sido maior na parte flamenga do país. Esses resultados sugerem que o verdadeiro impacto desse tipo de iniciativa, embora limitado, não deveria ser negligenciado.

Quantas pessoas a mais votaram em mulheres em 1999, em comparação com 1995? Ou, em outras palavras, as pessoas queriam realmente ver mais mulheres participando da política, desconsiderando o partido político em que votaram? Entre 1995 e 1999, o número de eleitores da Valônia que escolheu "somente homens" diminuiu em quase 50\% (de 38 para 20\%). Embora a porcentagem dos que votaram apenas em mulheres não tenha mudado essencialmente (cerca de 7\%), a porcentagem dos que votaram em ambos, homens e mulheres, aumentou $20 \%$ (de 54 para 74\%). Uma tendência semelhante, mas mais fraca, ocorreu entre os eleitores flamengos. Em 1995, 49\% dos eleitores votaram exclusivamente em homens, voto que se repetiu em 1999 por 35\% do eleitorado (uma diminuição de 14 pontos). Nesta última data, 12\% votaram apenas em mulheres (um aumento de 2 pontos em relação à data anterior). A porcentagem de eleitores que escolheram homens e mulheres aumentou cerca de 10 pontos (de 42 para 53\%). O voto exclusivo em homens permaneceu forte, todavia, em Flandres e na Valônia.

A atitude em relação ao papel feminino na política também mudou, tornando-se mais positiva, especialmente entre os eleitores do sexo masculino.

\footnotetext{
${ }^{7}$ Miet Smet é membro do CVP (Partido Democrata Cristão) e foi ministra do Trabalho e das Oportunidades Iguais no período legislativo de 1995-99.

${ }^{8}$ Fonte de dados: ISPO-PIOP, 1995 and 1999 General Election Study Belgium, Leuven/Louvain-la-Neuve. Apoiado pelos Serviços Federais para Negócios Técnicos, Culturais e Científicos (SSTC).
} 
Ambas as pesquisas ${ }^{9}$ incluíram uma série de escalas de cinco pontos que iam de "concordo completamente" a "discordo completamente" e mediam as atitudes em relação aos papéis das mulheres na política. Foram apresentados os seguintes conceitos: "Na política, as mulheres são mais eficientes para tratar dos interesses femininos"; "A política deve ser deixada para os homens"; "Tenho mais confiança em políticos homens"; "A política melhoraria se nela houvesse mais mulheres"; "Metade dos políticos eleitos deveria ser de mulheres"; "As mulheres são tão apropriadas à política quanto os homens"; e "Mais mulheres na política, mais democracia" (esta última foi incluída somente em 1999).

De acordo com a maioria do eleitorado, as mulheres estão mais equipadas do que os políticos homens para representar os interesses femininos. Deve-se observar que a porcentagem dos que pensavam assim em 1999 foi menor (62\%) do que em 1995 (65\%). Porém, houve um aumento no número daqueles que discordam das seguintes afirmações: "A política deve ser deixada para os homens" e "Tenho mais confiança em políticos homens". Os respondentes flamengos, tanto do sexo feminino como do masculino, hesitaram diante da afirmação de que "a política melhoraria se nela houvesse mais mulheres"(42\% e 44\% em 1999, novamente de maneira respectiva). Na Valônia, houve um nível semelhante de hesitação entre os respondentes do sexo masculino (40\% em 1999), mas uma maioria relativa de mulheres (41\%) concorda com essa afirmação. Mais de $80 \%$ do eleitorado belga acreditam que as mulheres são tão apropriadas à política quanto os homens, e uma relativa maioria (48\%) sustenta ainda que metade dos representantes deveria ser do sexo feminino. Por fim, em contraste com a maioria relativa (49\% em 1999) dos respondentes valões que concordam com a frase "mais mulheres na política, mais democracia", os eleitores flamengos são mais céticos com respeito à afirmação. Em 1999, apenas 33\% deles concordaram e 43\% responderam "não concordo nem discordo". A principal conclusão a ser tirada das atitudes expressas é que a maioria dos respondentes quer mais mulheres na política. Eles não querem que a política seja deixada exclusivamente para os homens e consideram as mulheres tão adequadas à política quanto os homens, pensando que metade dos representantes deveria ser do sexo feminino. Por que têm essa opinião? Uma vez que o eleitorado não parece acreditar que as mulheres melhorariam a política e a democracia, essas atitudes não parecem ser determinadas por argumentos utilitários. Pode-se concluir, então, que suas atitudes são influenciadas por suas crenças sobre direitos para certos grupos?

Considerando-se as atitudes positivas com respeito à participação feminina na política, o número de mulheres no Parlamento belga permanece estranhamente baixo, somente $23 \%$. O que está impedindo que mais mulheres sejam eleitas para o

\footnotetext{
${ }^{9}$ Neste caso, os dados vêm também dos Estudos Eleitorais Belgas de 1995 e 1999.
} 
Parlamento?

\section{Algumas características fundamentais do status político das mulheres belgas}

Na Bélgica, os direitos das mulheres de votar e serem votadas foram obtidos progressivamente (Mateo Diaz e Aish, 1999). Em 1921, elas conseguiram o direito de se candidatar em eleições locais, provinciais e legislativas. No mesmo ano, a primeira mulher foi cooptada para ser membro do Senado. Em 1948, foi concedido o direito de votar a todas as mulheres (Union Interparlementaire, 1995, p.78). Elas votaram pela primeira vez em 1949, 28 anos depois dos homens. Em maio de 1994, quase cinqüenta anos depois, o governo belga decidiu introduzir cotas na composição das listas eleitorais, numa ação legal em favor dos direitos políticos das mulheres.

Além das reformas do sistema eleitoral, outros organismos específicos foram criados para combater as disparidades entre homens e mulheres. Desde 1985, a Bélgica tem um Secrétariat d'État à l'Emancipation sociale, com sua própria administração e com orçamento próprio. Para esse Secretariado, "a participação das mulheres no processo de tomada de decisões constitui um dos principais eixos da política de emancipação das mulheres. Os outros dois eixos principais são a integração das mulheres na vida socioeconômica e a eliminação da violência contra as mulheres e as crianças". Desde janeiro de 1987, há um comitê para a emancipação social na Câmara de Deputados, cuja missão é dar recomendações, por iniciativa própria ou seguindo um pedido da Câmara (Union Interparlementaire, 1992, p.50). O Comité d'avis pour l'égalité des chances entre les hommes et les femmes, que pertence ao Senado, foi criado a 18 de janeiro de 1996, em conseqüência de um proposta feita por todas as senadoras após a conferência de Beijing da ONU sobre direitos das mulheres.

Ao olhar para a evolução do número de mulheres membros do Parlamento (MP) na Bélgica (Figura 1), podemos observar que, em geral, a porcentagem de mulheres aumentou a cada eleição entre 1946 e 1999. As exceções são as eleições de 1965, 1971 e 1981, em que os partidos que perderam mandatos eram os que costumavam ter mais representantes do sexo feminino. 
Figura 1. Evolução do número de mulheres MPs na Bélgica entre 1946-1999 ${ }^{10}$.

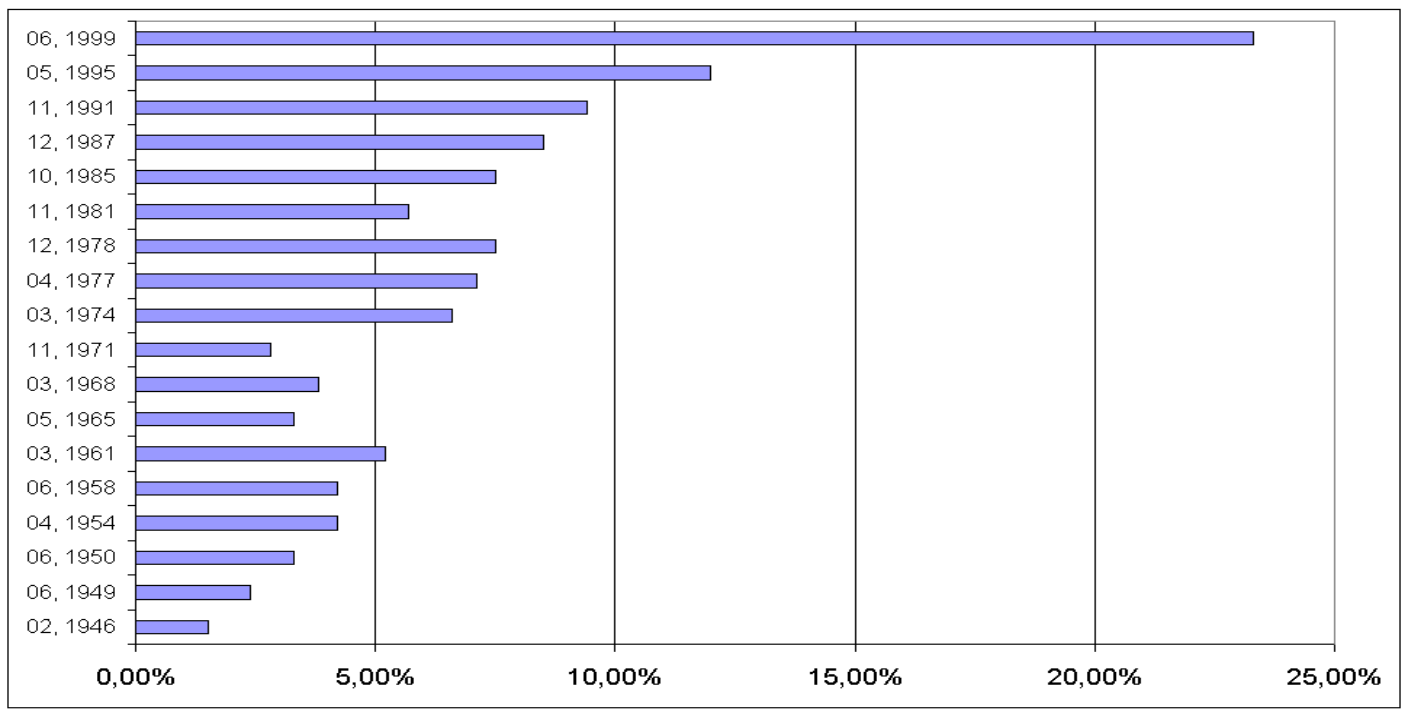

Hoje, a proporção de mulheres MPs é mais de três vezes a da metade da década de 1970. Gubin e Van Molle (1998) destacam que a eleição de 1974 significou uma mudança importante nas carreiras políticas das mulheres. Nessa eleição, os partidos políticos decidiram aumentar o número de mulheres em suas listas, em reação a pressões do Parti Féministe Unifié e à campanha Votez femme (Celis et al, 1998, p.35). Contudo, não houve um grande aumento do número de mulheres no Parlamento belga até a eleição de 1999. As representantes mulheres constituíam 6,6\% em 1974, 12\% em 1995 e 23\% em 1999.

A aprovação da legislação sobre paridade na França reabriu e reacendeu a discussão na Bélgica. Sob o rótulo de "dupla paridade", o país está agora a caminho de adotar uma fórmula progressiva e provisória para atingir o equilíbrio entre os sexos na arena política. Além disso, foi criado um comitê de renovação política, constituído por membros do Senado e da Câmara ${ }^{11}$. Seu principal objetivo é deliberar sobre regras que possam aperfeiçoar a democracia belga em questões como a do funcionamento das instituições (Senado e Câmara), composição das listas partidárias por sexo, alargamento do eleitorado ou o uso de um referendo. É interessante observar que as mulheres são consideradas um fator de mudança na democracia da Bélgica e, portanto, espera-se que assim funcionem ${ }^{12}$. A igualdade

\footnotetext{
${ }^{10}$ Os dados são de Union Interparlementaire, 1995, completados com números do website IPU consultados em 15/01/2001.

${ }^{11}$ Ver intervenção de Luc Pâque, PSC, em Handelingen van de Plenaire Vergaderingen, De Kamer, 21.12.1999.

${ }^{12}$ Senado belga, 28 de março de 2000. Intenções da política geral de Mme. Laurette Onkelinx, vice-primeira-ministra e ministra do Trabalho e Oportunidades Iguais entre homens e mulheres. Recomendação feita pelo Comitê de Recomendação sobre oportunidades iguais entre homens e mulheres. Relatório feito pelos srs. Lizin e De Bethune.
} 
entre gêneros tornou-se uma fonte potencial de renovação política ${ }^{13}$.

Antes de analisar os efeitos da lei Smet-Tobback sobre a eleição de 1999, é preciso examinar o modo como as cotas foram aplicadas em cada partido político.

\section{Cotas nos partidos políticos ${ }^{14}$}

Qual é a posição dos diversos partidos políticos belgas com respeito às cotas? Verzele e Joly (1999, p.79-80) classificam-nos em quatro tendências principais: "partidos que defendem uma extensão de medidas precisas a fim de alcançar a paridade (partidos verdes, democratas-cristãos e VU-ID); partidos que recusam as cotas e propõem a supressão ou neutralização do efeito de devolução do 'topo da lista' (effet dévolutif de la case de tête) ${ }^{15}$ como uma solução para o problema da sub-representação feminina (partidos liberais); partidos a favor da paridade, sem propor medidas específicas (partidos socialistas); um partido que quer abolir qualquer idéia de cota, sem nenhuma proposta sobre a questão (Vlaams Blok)".

Antes da adoção da lei geral que impôs cotas na composição das listas, alguns partidos haviam implementado o sistema por conta própria. Nas eleições de 1995, o partido democrata cristão francófono (PSC) ${ }^{16}$ aplicou uma cota máxima de 2/3 para cada sexo. Desde 1992, o partido socialista flamengo (SP) reservou um quarto de seus assentos para mulheres em suas listas eleitorais. Desde cedo, as mulheres democratas cristãs flamengas (CVP) lutaram para aumentar sua presença na política. Em vez de usar cotas obrigatórias, desde 1974 o CVP tomou várias medidas para aumentar o número de mulheres, tais como recomendações sobre as posições e reservar um mínimo de $20 \%$ para candidatas do sexo feminino na lista. Os outros partidos não implementaram cotas. Em 1993, o partido verde flamengo (Agalev) ratificou a paridade. Porém, nenhuma mulher deste partido obteve assento no Parlamento (0/4) na eleição de 1995. Em 1992, o partido liberal flamengo (VLD) aboliu o regulamento estatutário que impunha um mínimo de $20 \%$ de mulheres nas listas eleitorais (Verzele e J oly, 1999). Nas eleições seguintes, a porcentagem de representantes do sexo feminino do VLD diminuiu consideravelmente. É importante sublinhar que as mulheres desses partidos foram responsáveis pela maioria das

\footnotetext{
13 “A dupla paridade será introduzida progressivamente. [...] Essa paridade será o primeiro elemento da renovação política que o governo busca." Minutas da Reunião de Gabinete. 19 de maio de 2000.

${ }^{14}$ Partidos socialistas: SP (Socialistische Partij); OS (Parti Socialiste). Partidos democratas-cristãos: CVP (Christelijke Volkspartij); PSC (Parti Social-Chrétien). Partidos liberais: VDL (Vlamse Liberalen em Democraten); PRL (Parti Réformateur Libéral). Partidos verdes: Agalev (Anders Gaan Leven, Arbeiden Em Vrijen); Ecolo (Ecologistes Confédérés pour l'Organisation de Luttes Originales). Partidos de extrema direita: VB (Vlaams Blok); FN (Front National). Partidos regionalistas: VU-ID (Volksunie).

Partido Socialista (desde 1977 dividido em OS e SP, francófono e flamengo respectivamente); Partido Católico (dividido desde 1965 em PSC e CPV); Partido Liberal (dividido desde 1971 em PRL e PVV).

${ }^{15} \mathrm{O}$ assim chamado "efeito de devolução" dá prioridade aos candidatos do topo da lista.

${ }^{16}$ Ratification d'un protocole additionnel au Congrès du 24 avril 1993.
} 
iniciativas que buscavam um equilíbrio entre os sexos nos partidos políticos que, com freqüência, acabaram em recomendações ou constrangimentos formalmente obrigatórios.

O partido verde francófono (Ecolo) não adotou nenhum constrangimento formal, mas recomendou paridade para as eleições de 1999. O partido liberal francófono (PRL), a $\mathrm{FDF}^{17}$ e o $\mathrm{MCC}^{18}$, partidos de coalizão, são contra o sistema de cotas, mas tiveram uma atitude positiva em relação à abolição do efeito de devolução do "topo da lista". O partido socialista francófono (PS) sempre relutou em adotar cotas no que se refere à composição das listas. Apesar de ter declarado que a paridade entre homens e mulheres é algo desejável, o PS jamais tomou qualquer medida nesse sentido. $\mathrm{O}$ grupo de mulheres do VU-ID (partido regionalista flamengo) sempre tentou colocar candidaturas femininas em boas posições, ainda que o partido jamais tenha mostrado atitudes positivas com respeito a qualquer ação particular para obter o equilíbrio entre os sexos. Por fim, o Vlaams Blok (partido de extrema direita flamengo) sempre foi contra qualquer tipo de cota. As Figuras seguintes mostram o número de mulheres no Parlamento por partido ao longo do tempo e dão uma imagem da eficácia das ações positivas empreendidas pelos partidos, possibilitando uma comparação com os resultados dos partidos que não tomaram tais medidas.

\footnotetext{
${ }^{17}$ Partido regionalista de Bruxelas (Front Démocratique des Francophones).

${ }^{18}$ Partido democrata cristão frnacófono (Mouvement des Citoyens pour le Changement).
} 
Figura 2. Partidos com obrigatoriedade formal ou recomendações sobre cotas/paridade 1971-1999

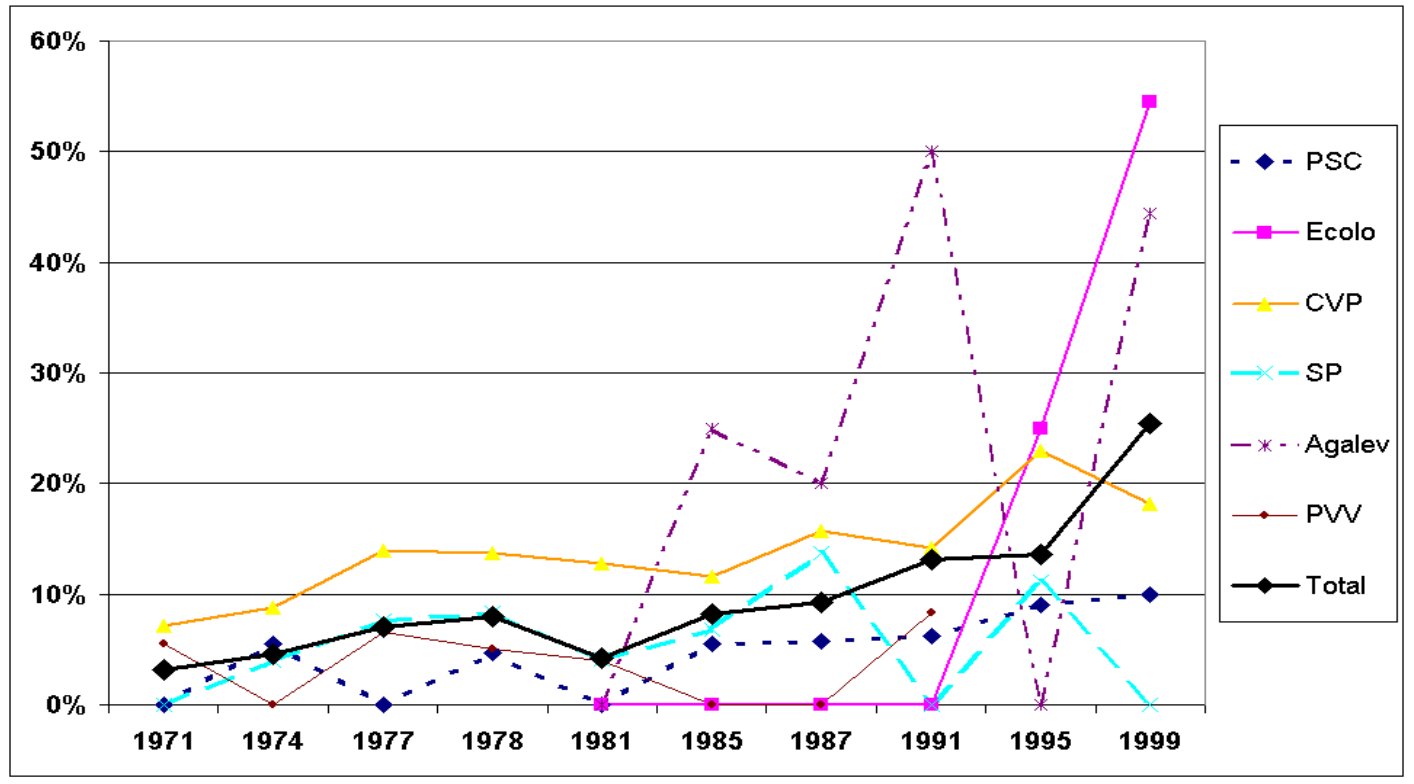

Figura 3. Partidos sem cotas/paridade 1971-1999

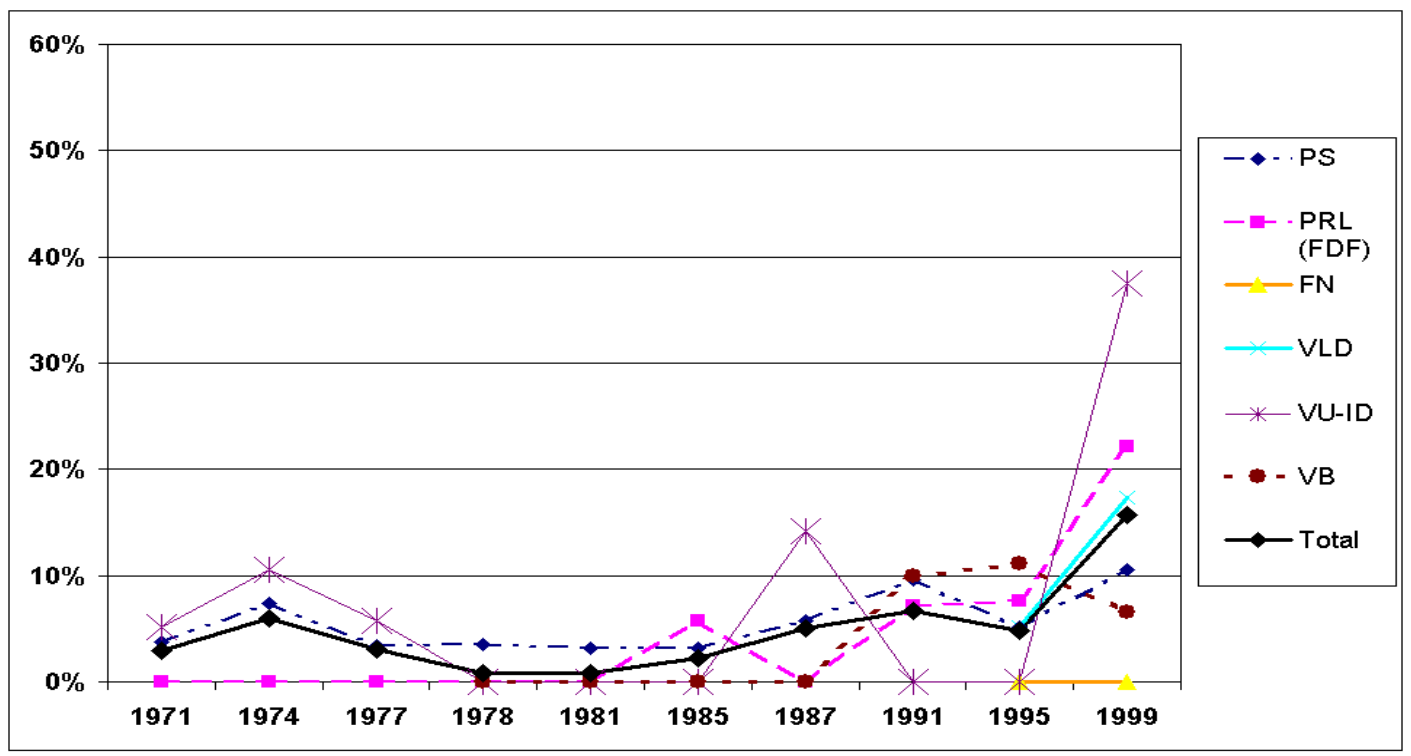

Depois das eleições de 1999, os partidos com as porcentagens mais altas de mulheres são os dois partidos verdes (Ecolo e Agalev) e o partido regionalista 
flamengo (VU-ID). O VU-ID não tem cotas e os dois partidos verdes têm um sistema de paridade (obrigatório no Agalev, recomendado no Ecolo). Como o VU-ID ilustra, a posição dos candidatos na lista parece ser mais decisiva do que o número de homens e mulheres per se. O partido liberal francófono (PRL) mostra um grande aumento entre 1995 e 1999, obtendo mais de $22 \%$ de representantes do sexo feminino sem qualquer imposição de cotas. Com ou sem cotas, os partidos flamengos democrata cristão (CVP) e liberal (VDL) vêm a seguir com 18\% e 17\% de mulheres respectivamente ${ }^{19}$. O PSC (democrata cristão francófono), com cotas, e o PS (socialista francófono), sem cotas, têm ambos cerca de $10 \%$. No fim da lista estão os partidos de extrema direita (VB e FN) e o partido socialista flamengo (SP).

Desse modo, em relação ao número de mulheres realmente eleitas, pode-se observar que alguns dos partidos sem cotas estão entre aqueles que possuem um equilíbrio maior entre os sexos, enquanto alguns dos partidos com sistema de cotas não apresentam equilíbrio algum. Uma representação equilibrada quanto ao gênero no Parlamento não é somente uma questão de número no interior da composição das listas mas também de ordem, entre os candidatos masculinos e femininos. Nesse sentido, os dois partidos verdes aplicaram o sistema de "zíper" na elaboração das listas (isto é, a alternação entre homens e mulheres), que está ligado ao interesse desses partidos em mudar, com ou sem a imposição de medidas como as cotas.

Há uma teoria conforme a qual "é mais provável que os partidos de esquerda indiquem e elejam candidatas" (Norris, 2000; Caul, 1999; Duverger, 1955). Como ficou demonstrado nesta seção, nem sempre é o caso. Na Bélgica, o partido socialista não foi o que mais apoiou, por exemplo, o sufrágio feminino. Ainda que se inspire numa ideologia igualitária, o medo de uma derrota eleitoral, devido à suposição de que o voto das mulheres é conservador, fez o pragmatismo político dominar (Gubin, 1998, p.69; Peemans-Poullet 1998, p. 16; Coenen 1998, p.42, 44).

\section{A lei Smet-Tobback}

A lei "Smet-Tobback" sobre cotas pretendia promover uma distribuição equilibrada de homens e mulheres nas listas de candidatos, estabelecendo um limite máximo por sexo de $2 / 3$ por grupo ${ }^{20}$. Qual foi o efeito da lei? Ou, em outras palavras, as cotas fazem diferença? Como?

A lei não diz nada a respeito da ordem em que os candidatos devem ser apresentados nas listas. Ela foi aplicada pela primeira vez em 9 de outubro de 1994, nas eleições provinciais e locais. Porém, uma cota temporária de $3 / 4$, em vez

\footnotetext{
${ }^{19}$ Como foi dito antes, o VDL aboliu as cotas em 1992.

${ }^{20}$ Le Moniteur Belge, $1^{\circ}$ de junho de 1994. Artigo 117bis da lei Eleitoral.
} 
de $2 / 3$, foi usada nessas eleições. A lei sobre cotas não estava vigente nas eleições gerais de 1995, mas foi plenamente aplicada nas eleições gerais, regionais e européias de 1999.

À primeira vista, as cotas afetaram fortemente a composição sexual do Parlamento. O número de mulheres aumentou de 12,7\% em 1995 para 23,3\% em 1999. A Figura 4 mostra a distribuição das mulheres por partido depois da eleição de 1999.

Figura 4. Porcentagem de mulheres eleitas diretamente para a Câmara Federal de Deputados por partido, 1999

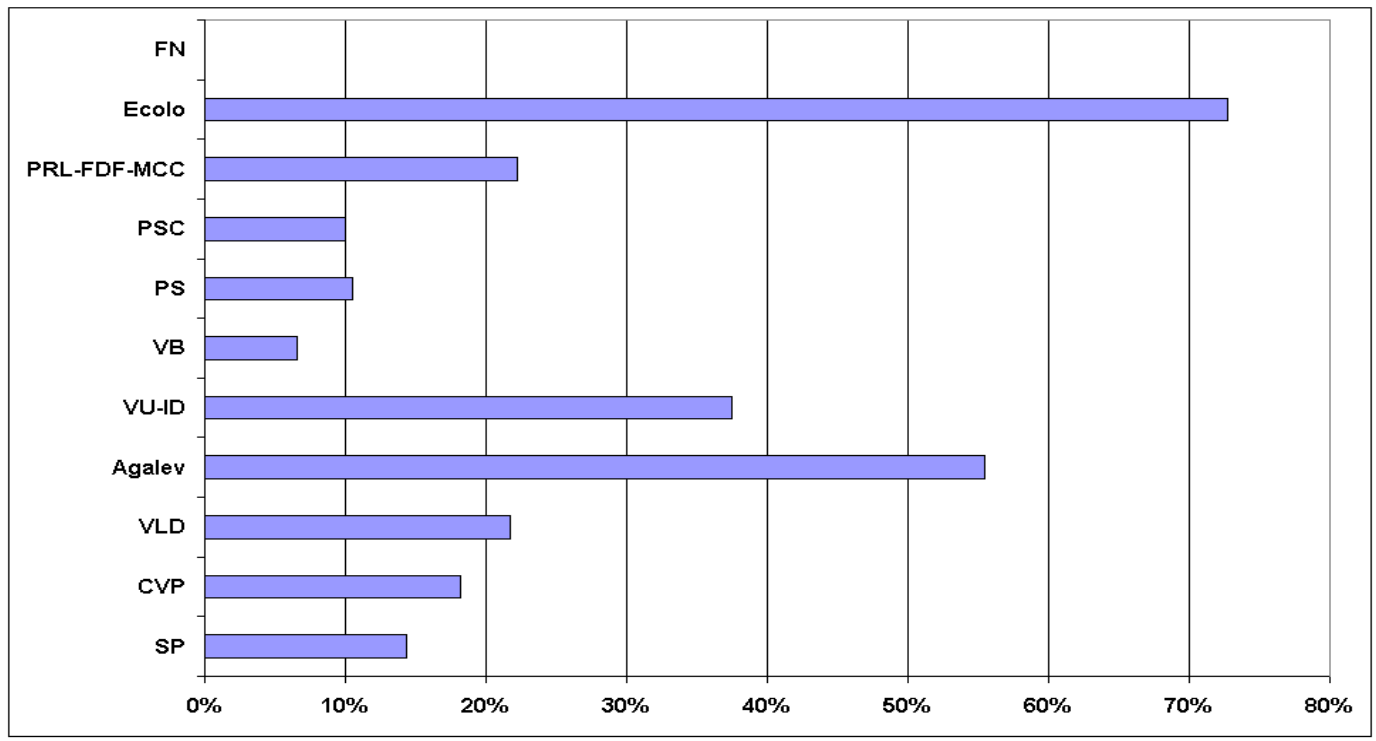

Em média, os partidos flamengos estão 2,5 pontos acima dos partidos francófonos, com $25,6 \%$ contra $23,1 \%$ de deputadas respectivamente. Os partidos verdes flamengo e francófono têm o maior número de representantes mulheres, seguidos pelo VU-ID. A representação igual entre os sexos foi alcançada e até ultrapassada pelo Ecolo. Na direção oposta, estão dois partidos de extrema direita (FN e VB), com uma presença feminina muito baixa, assim como o PSC (democrata cristão francófono) e os partidos socialistas (PS e SP). Por outro lado, ainda que os partidos liberais (VLD e PRL) sempre tenham sido contra as cotas, mais de $20 \%$ de seus representantes são mulheres.

Uma explicação dessa variação, que pode esclarecer o efeito das cotas, bem como o de outros fatores, exige uma análise mais profunda de todo o processo, da composição sexual das listas à composição final do Parlamento. As próximas quatro sub-seções apresentam: (1) o número de homens e mulheres nas listas dos 
partidos; (2) o número de homens e mulheres em posições elegíveis; (3) o número de homens e mulheres eleitos; e (4) o número efetivo de homens e mulheres no Parlamento.

\section{O número de homens e mulheres nas listas dos partidos}

As listas apresentadas pelos partidos estão organizadas em torno de duas categorias de candidatos: efetivos e suplentes ${ }^{21}$. Um suplente entra para o Parlamento somente se um dos candidatos efetivos renunciar após ser eleito (por exemplo, ele/ela foi nomeado/a ministro/a). Para essa parte da análise, as posições dentro das listas partidárias não são levadas em conta.

A Figura 5 mostra que todas as listas cumpriram o 1/ 3 estabelecido pela lei. Em média, tanto os partidos flamengos como os francófonos têm cerca de $40 \%$ de candidatas. Os partidos verdes têm as listas mais equilibradas quanto ao sexo. Comparada com 1995, a porcentagem de candidatas efetivas aumentou de $32 \%$ para 39\% em todo o país. Quanto aos partidos francófonos, em 1995 tinham um pouco menos de mulheres candidatas efetivas (3\%), em 1999 as proporções eram as mesmas.

Figura 5. Mulheres candidatas em posições efetivas e suplentes nas listas dos partidos nas eleições para a Câmara de Deputados da Bélgica, 1999

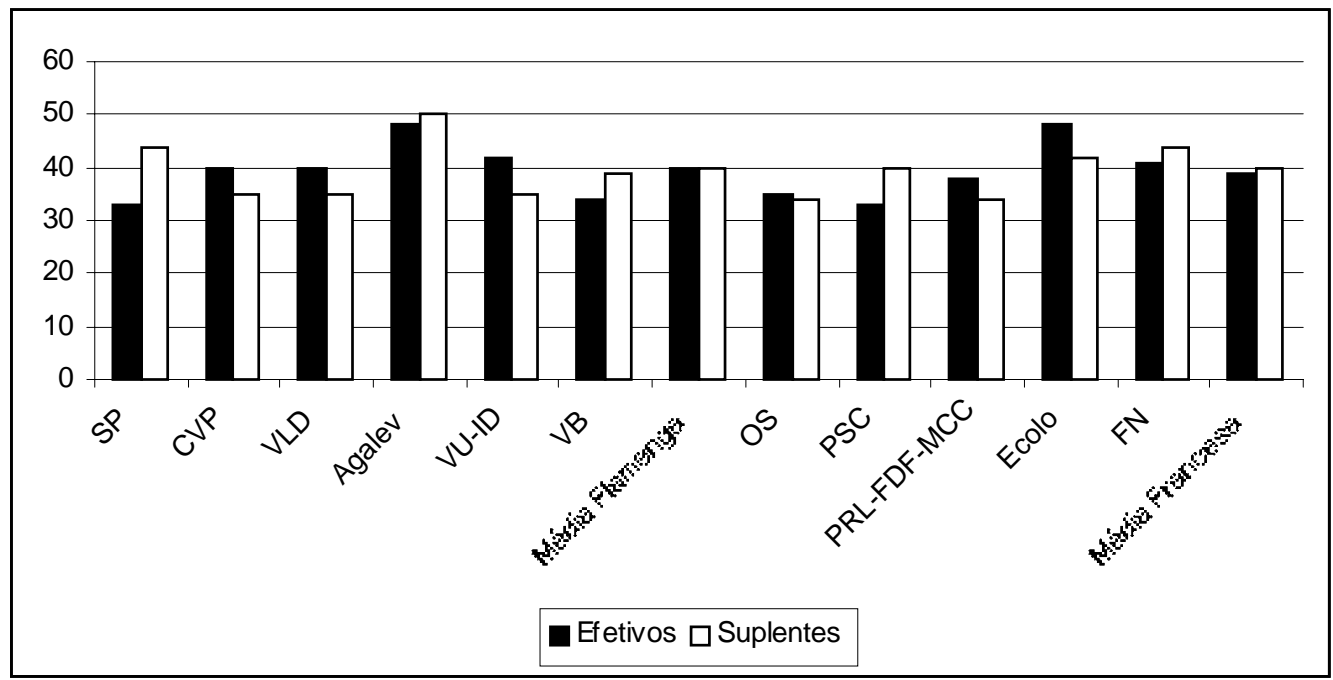

Até agora, há poucos indícios de variação entre partidos. Porém, a mudança no número de mulheres efetivamente eleitas por partido em 1999 sugere que a

\footnotetext{
${ }^{21}$ Art. 117 da Lei Eleitoral.
} 
classificação por sexo nas listas tem pouca relação com o grau de igualdade sexual dessas listas. A posição que os candidatos ocupam nas listas está longe de ser trivial. Tendo em vista a importância da ordem no sistema eleitoral belga, isso não surpreende. Uma vez que a obrigatoriedade está relacionada apenas com a quantidade de mulheres incluídas nas listas, cabe aos partidos decidirem se põem as mulheres em posições elegíveis ou não.

\section{O número de homens e mulheres em posições elegíveis}

Ao olhar para as posições nas listas, dois aspectos importantes devem ser considerados. Em primeiro lugar, deve-se distinguir entre posições elegíveis e nãoelegíveis (isto é, a ordre utile). As posições elegíveis são calculadas com base nos assentos obtidos pelo partido na última eleição. Em segundo lugar, o efeito de devolução que beneficia os candidatos situados no topo da lista, independente do número de votos obtidos ${ }^{22}$. Esses dois aspectos afetam negativamente os candidatos que ocupam as posições mais baixas da lista, geralmente as mulheres. Esse efeito negativo é reforçado ainda pela existência de duas categorias de candidatos, a dos efetivos e dos suplentes, esta última também freqüentemente ocupada por mulheres.

\section{Topo das listas}

A Tabela 1 mostra o número de mulheres que ocuparam posições de topo nas listas apresentadas pelos partidos. A Bélgica tem onze arrondissements (distritos eleitorais) flamengos e dez francófonos que influenciam o número de listas apresentadas pelos partidos.

\footnotetext{
${ }^{22}$ Art. 172 da Lei Eleitoral.
} 
Tabela 1. Porcentagem de mulheres no topo das listas em 1995 e em 1999 (números absolutos entre parênteses)

\begin{tabular}{|l|c|c||}
\cline { 2 - 3 } \multicolumn{1}{c|}{} & $\begin{array}{c}\text { Porcentagem de mulheres no topo da lista } \\
\text { 95 }\end{array}$ & $\begin{array}{c}\text { Porcentagem de mulheres no topo } \\
\text { da lista 99 }\end{array}$ \\
\cline { 2 - 3 } \multicolumn{1}{c|}{} & Sim & Sim \\
\hline \hline VLD & $0(0 / 11)$ & $0(0 / 11)$ \\
\hline PRL(FDF) & $0(0 / 10)$ & $20(2 / 10)$ \\
\hline \hline CVP & $0(0 / 11)$ & $9.09(1 / 11)$ \\
\hline \hline PSC & $20(2 / 10)$ & $10(1 / 10)$ \\
\hline SP & $0(0 / 11)$ & $0(0 / 11)$ \\
\hline PS & $10(1 / 10)$ & $0(0 / 10)$ \\
\hline \hline Agalev & $54.55(6 / 11)$ & $36.36(4 / 11)$ \\
\hline Ecolo & $10(1 / 10)$ & $50(5 / 10)$ \\
\hline \hline VU & $9.09(1 / 11)$ & $27.27(3 / 11)$ \\
\hline \hline Vlaams Blok & $0(0 / 11)$ & $0(0 / 11)$ \\
\hline \hline FN & $22.22(2 / 9)$ & $10(1 / 10)$ \\
\hline \hline Total & $11.30(13)$ & $14.66(17)$ \\
\hline \hline
\end{tabular}

Há uma evolução positiva da média geral de todos os partidos de 1995 para 1999. Porém, o número de mulheres que encabeçam as listas ainda é muito baixo (em torno de 15\%). Três partidos, VLD, SP e VB, não apresentam mulheres nessas posições em nenhuma eleição. Em 1999, a porcentagem de mulheres no topo caiu no PSC, PS, FN e Agalev. Mesmo que a porcentagem no Agalev tenha diminuído entre as duas eleições, ele ainda apresenta a tendência mais forte de pôr mulheres no topo da lista, ao lado do outro partido verde (Ecolo).

É óbvio que um candidato precisa ocupar uma das primeiras posições das listas para aumentar suas chances de ser eleito. Porém, estar numa posição do topo não importa realmente se o partido não tem chances de ganhar um assento em um determinado distrito eleitoral. Por isso, a análise do equilíbrio entre os sexos em posições elegíveis das listas pode ajudar mais a explicar o resultado, ou seja, o número de mulheres diretamente eleitas.

\section{Posições elegíveis}

O número de mulheres em posições que o partido espera que se transformem em assentos no Parlamento pode ser conhecido aplicando-se os resultados de 1995 às listas de candidatos de 1999. Evidentemente, pressupõe-se 
que os partidos esperavam pelo menos manter os resultados da eleição anterior em cada distrito. O mesmo procedimento foi usado para calcular a porcentagem de mulheres colocadas pelos partidos em posições elegíveis em 1995, de tal forma que os resultados de antes e de depois da aplicação da lei pudessem ser comparados. O principal problema desse procedimento é que o número de assentos do Parlamento em 1991 (212) era diferente do de 1995 (150). Isso significa que se o partido X obteve 5 assentos em 1991 num determinado distrito, que teve seu número de assentos reduzido de 20 para 14, esse número, com o mesmo resultado eleitoral não seria mais 5, mas 3,5. Uma maneira de resolver o problema é ponderar os resultados de 1991 por partido e torná-los equivalentes, em termos de número de assentos, àqueles disponíveis em 1995 e 1999. No entanto, ainda que faça sentido matemático, esse procedimento apresenta vários problemas práticos.

O primeiro deles é a dificuldade de como distribuir um meio assento numa lista de candidatos. O segundo pode ser explicado com o seguinte exemplo: se um partido apresentou mulheres nas posições quatro e cinco em 1995, poder-se-ia dizer que $40 \%$ dos candidatos em posições elegíveis eram mulheres. Porém, o partido tem agora 1,5 assentos a menos devido à redução geral de assentos de $30 \%$ para todos os distritos. Quando os resultados são ponderados, o número de mulheres em posições elegíveis ainda é superestimado: 1,4 candidatas em 3,5 assentos ainda significa $40 \%$, mas a porcentagem real seria provavelmente de $0 \%$. Devido a esses problemas, os casos foram reexaminados. Um exemplo semelhante foi tratado com uma redução de dois assentos, o que implica que nenhuma candidata estava em posição elegível. Em termos gerais, se os decimais eram menores do que 0,5, o número de assentos foi arredondado para baixo. Isso significa uma subestimação do número de mulheres em "ordem útil". Para compensar isso, se o partido $X$ teve um assento no distrito B em 1991, ele foi mantido em 1995. Isso significa que se uma candidata está numa posição de topo em 1995, o partido terá uma candidata em posição elegível naquele distrito determinado. Nos casos em que os decimais eram acima de 0,5, o número de assentos foi arredondado para cima. Esse segundo caso dá uma superestimação do número de mulheres em "ordem útil", e ambos os erros provavelmente se anulam.

Os dados sugerem que o número de mulheres em posições elegíveis entre as duas eleições diminuiu levemente. Porém, essa diferença tem de ser considerada com precaução. Já foi mencionado que o tamanho da Câmara mudou de 1991 para 1995, o que torna difícil saber o número exato de posições elegíveis em 1995. 
Tabela 2. Comparação entre o número de mulheres em posições elegíveis nas listas apresentadas por partido em $1995 \mathrm{e} \mathrm{em} 1999^{23}$

\begin{tabular}{|l|c|c|c||c||}
\cline { 2 - 5 } \multicolumn{1}{c|}{} & \multicolumn{2}{c|}{$\begin{array}{c}\text { Número de mulheres em } \\
\text { posições elegíveis }\end{array}$} & $\begin{array}{c}\text { Médias das porcentagens de } \\
\text { mulheres/partidos em } \\
\text { posições elegíveis }\end{array}$ \\
\cline { 2 - 5 } \multicolumn{1}{l||}{} & 1995 & 1999 & 1995 & 1999 \\
\hline VLD & 2 & 3 & $7.58(11)$ & $12.12(11)$ \\
\hline PRL(FDF) & 4 & 3 & $9.72(9)$ & $13.33(9)$ \\
\hline CVP & 8 & 10 & $24.24(11)$ & $34.85(11)$ \\
\hline PSC & 3 & 2 & $25.93(9)$ & $16.67(9)$ \\
\hline SP & 3 & 2 & $10.61(11)$ & $6.06(11)$ \\
\hline PS & 5 & 3 & $15(10)$ & $10.83(10)$ \\
\hline Agalev & 2 & 0 & $66.67(3)$ & $0(5)$ \\
\hline Ecolo & 2 & 1 & $0(5)$ & $20(5)$ \\
\hline VU & 1 & 2 & $37.5(4)$ & $40(5)$ \\
\hline Vlaams Blok & 1 & 1 & $6.67(5)$ & $3.57(7)$ \\
\hline FN & 31 & 27 & $16.93(78)$ & $15.14(85)$ \\
\hline \hline Total & 2 & 0 & & $0(2)$ \\
\hline
\end{tabular}

Nota: Os números entre parênteses representam o número de listas por partido com posições elegíveis.

Qualquer que seja o valor exato da diferença, está claro que as oportunidades reais para as mulheres não melhoraram de 1995 para 1999. Na verdade, o partido democrata cristão (PSC), dois partidos socialistas (SP e PS), o partido verde flamengo (Agalev) e o partido de extrema direita flamengo (VB) reduziram a porcentagem de mulheres em posições elegíveis em 1999. A mudança mais notável foi a do Agalev, que tinha mais de 60\% de mulheres em 1995 e diminuiu para zero em 1999.

Além da própria cota, podemos esperar que o equilíbrio entre os sexos seja afetado por dois outros fatores: (1) aumento ou redução do número de assentos de um partido entre duas eleições; e (2) a posição do partido com respeito à igualdade entre os gêneros.

Quanto ao primeiro fator, e uma vez que a tendência geral dos partidos é colocar homens no topo das listas e as mulheres em posições não elegíveis, as

\footnotetext{
${ }^{23}$ Os valores nas terceira e quarta colunas são a média da porcentagem de mulheres elegíveis por partido e por distrito. Isso significa que a porcentagem de mulheres foi calculada a partir do número total de posições elegíveis que um partido teve em cada distrito, e depois a média total para o partido foi feita. Outro modo de calcular é computar o número total de mulheres elegíveis e o total de posições elegíveis, e então calcular a porcentagem a partir desses dois valores. Por exemplo, em 1999, o VLD tinha 3 mulheres elegíveis em 21, ou seja $14.29 \%$ das mulheres em posições elegíveis. Se fizermos o mesmo para cada partido e depois calcularmos a média, obtemos um total de $15.65 \%$ de mulheres em posições elegíveis (17.2\% sem incluir a FN).
} 
mulheres têm menos chances de se elegerem, exceto no caso de um sucesso inesperado do partido nas eleições. Se isso é verdade, podemos esperar que os partidos que ganharam assentos entre 1995 e 1999 serão aqueles com uma diferença positiva mais alta entre o número de mulheres diretamente eleitas e aquelas em posições elegíveis nas listas. O mesmo valeria para as eleições de 1995 em comparação com 1991. A Figura seguinte mostra as porcentagens obtidas pelos partidos nas eleições de 1991, 1995 e 1999.

Figura 6. Resultados das eleições em 1991, 1995 e 1999 para a Câmara de Deputados da Bélgica

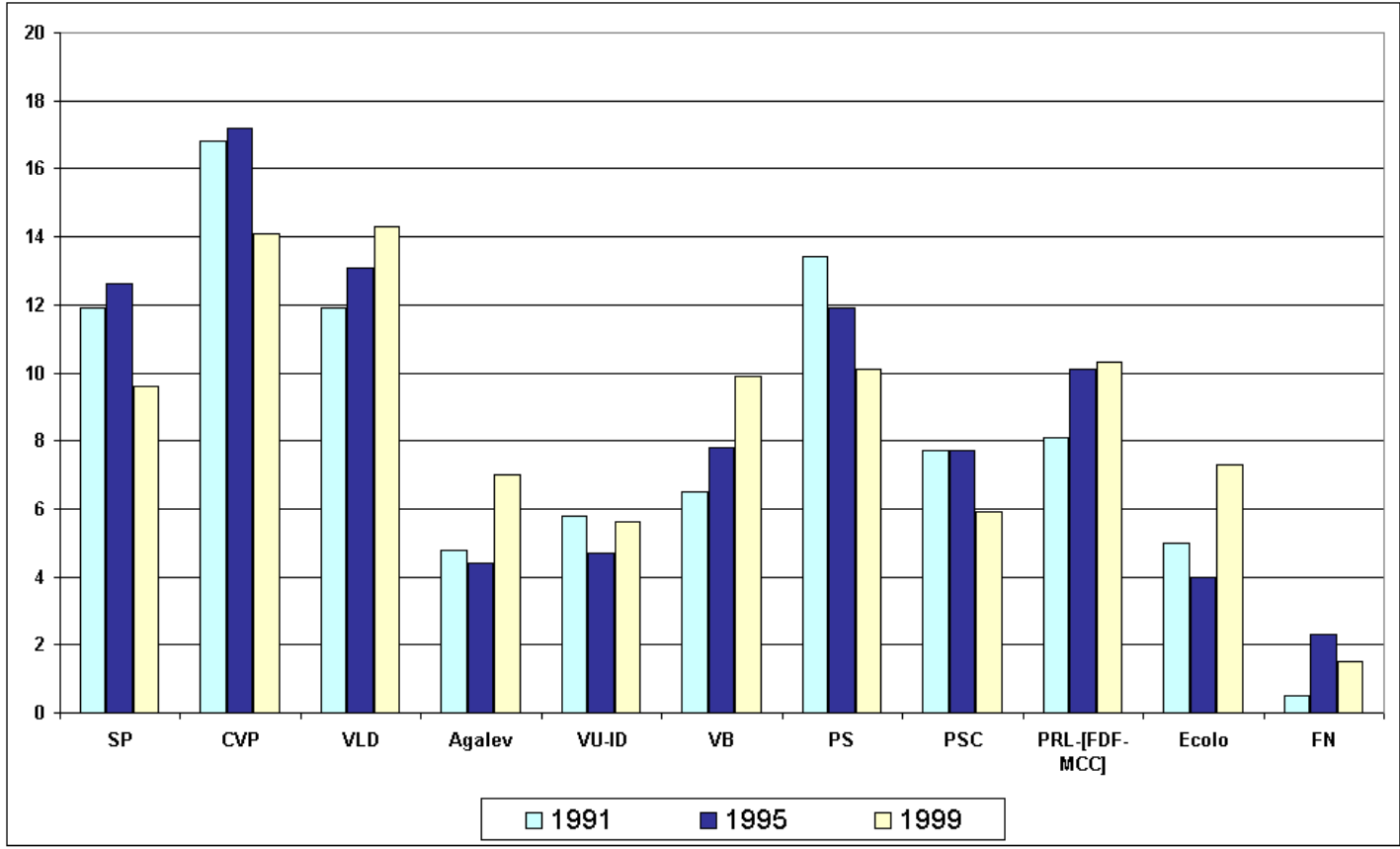

Em comparação com os resultados de 1991, SP, CVP, VLD e especialmente PRL e FN ganharam votos nas eleições de 1995, enquanto VU, PS e os dois partidos verdes perderam assentos. De 1995 para 1999, os partidos que aumentaram seus votos foram Ecolo, Agalev, VLD, VU-ID, Vlaams Blok e, em menor medida, PRL. Assim, se é verdade que há uma relação entre os ganhos eleitorais de um partido e o número de mulheres eleitas, em 1999 deveria haver um aumento na diferença entre o número de mulheres diretamente eleitas e o número de mulheres em posições elegíveis nos referidos partidos. A tendência oposta deveria aparecer nos outros partidos, que tiveram menos sucesso em 1999, isto é, SP, CVP, PS, PSC e FN. Considerando-se que as mulheres são colocadas freqüentemente no final das 
listas, quando os partidos ganham mais assentos do que os esperados, as mulheres assumem as assim chamadas "posições de briga" (positions de combat), ou seja, os primeiros lugares logo depois das posições elegíveis.

Uma maneira simples de analisar se essas suposições estão corretas ou não é correlacionar a diferença entre o número de mulheres diretamente eleitas e em posições elegíveis e os ganhos/perdas eleitorais dos partidos entre duas eleições consecutivas. Um coeficiente negativo (isto é, valores mais altos em um eixo resultam em valores menores no outro) indica que se um partido tem ganhos eleitorais, há uma chance proporcionalmente maior de que suas candidatas sejam eleitas.

A Tabela 3 apresenta as diferenças entre 1991 e 1995 e as diferenças entre 1995 e 1999. Na primeira coluna, as correlações de Pearson foram calculadas para todos os partidos. Outro aspecto digno de estudo é a diferença entre os partidos com e sem ações positivas. Assim, na segunda coluna foram calculados dois coeficientes suplementares: um para os partidos que haviam implementado ações positivas para a igualdade entre gêneros antes da lei geral e outro para os que não haviam feito isso.

Em termos gerais, quando os partidos perdem assentos, o número de mulheres eleitas diminui num grau desproporcionalmente alto, o que sugere que as mulheres estão ocupando a parte mais baixa das posições elegíveis, ou "posições de briga".

Tabela 3. Correlações de Pearson para 1995 e 1999, mostrando a mudança no número de assentos dos partidos de 1991 e 1995, respectivamente, e as diferenças entre o número de mulheres diretamente eleitas e em posições elegíveis

\begin{tabular}{|c|c|c|c|c|}
\hline & \multicolumn{4}{|c|}{$\begin{array}{c}\text { Diferença entre o número de mulheres diretamente eleitas } \\
\text { e em posições elegíveis }\end{array}$} \\
\hline & \multicolumn{2}{|c|}{ 1995-antes das cotas $(\mathrm{N}=115)$} & \multicolumn{2}{|c|}{$1999-$ com a lei sobre cotas $(\mathrm{N}=116)$} \\
\hline \multirow{2}{*}{$\begin{array}{l}\text { Diferença entre o número de assentos } \\
\text { (91-95 e 95-99 respectivamente) }\end{array}$} & \multicolumn{2}{|c|}{$-.589^{* *}$} & \multicolumn{2}{|c|}{$-.693^{* *}$} \\
\hline & $\begin{array}{l}\text { Partidos sem } \\
\text { ações pos. } \\
(\mathrm{N}=62)\end{array}$ & $\begin{array}{l}\text { Partidos com } \\
\text { ações pos. } \\
(\mathrm{N}=53)\end{array}$ & $\begin{array}{l}\text { Partidos sem } \\
\text { ações pos. } \\
(\mathrm{N}=62)\end{array}$ & $\begin{array}{l}\text { Partidos com } \\
\text { ações pos. } \\
(\mathrm{N}=53)\end{array}$ \\
\hline $\begin{array}{l}\text { Diferença entre o número de assentos } \\
\text { (91-95 e } 95-99 \text { respectivamente) }\end{array}$ & $-.671^{\star *}$ & $-.467^{\star *}$ & $-.419^{* *}$ & $-.813^{* *}$ \\
\hline
\end{tabular}

** Correlação é significativa no nível 0.01 (bicaudal).

* Correlação é significativa no nível 0.05 (bicaudal).

$\mathrm{N}=$ número de listas apresentadas pelos partidos. 
A utilização de ações positivas dentro de um partido causa algum efeito sobre um número de mulheres que são diretamente eleitas ou que estão em posições elegíveis? Os coeficientes em 1995 (-.671 e -.467) indicam que a diferença entre partidos que implementaram cotas ou outras medidas e os outros partidos não é grande. Porém, essa diferença é maior em 1999. Nessa eleição, o coeficiente para partidos que aplicam medidas de igualdade de gênero (CVP, PSC, SP, Agalev e Ecolo) é muito alto (-.813). Isso indica que a aplicação de ações positivas pode aumentar o número de deputadas eleitas em relação ao total do ganho do partido.

\section{O número de homens e mulheres eleitos ${ }^{24}$}

Mesmo que a lei afete apenas a lista de candidatos, o objetivo último é obter um Parlamento mais equilibrado em termos de sexo. A subtração na porcentagem de mulheres membros do Parlamento (MP) por partido em 1995 daquela de 1999 deveria, hipoteticamente, ser positiva para 1999. Além disso, uma vez que a lei era a mesma para todos os partidos, o efeito deveria ser também o mesmo para todos eles.

Figura 7. Diferenças na porcentagem de mulheres MPs entre 1995 e 1999 por partido

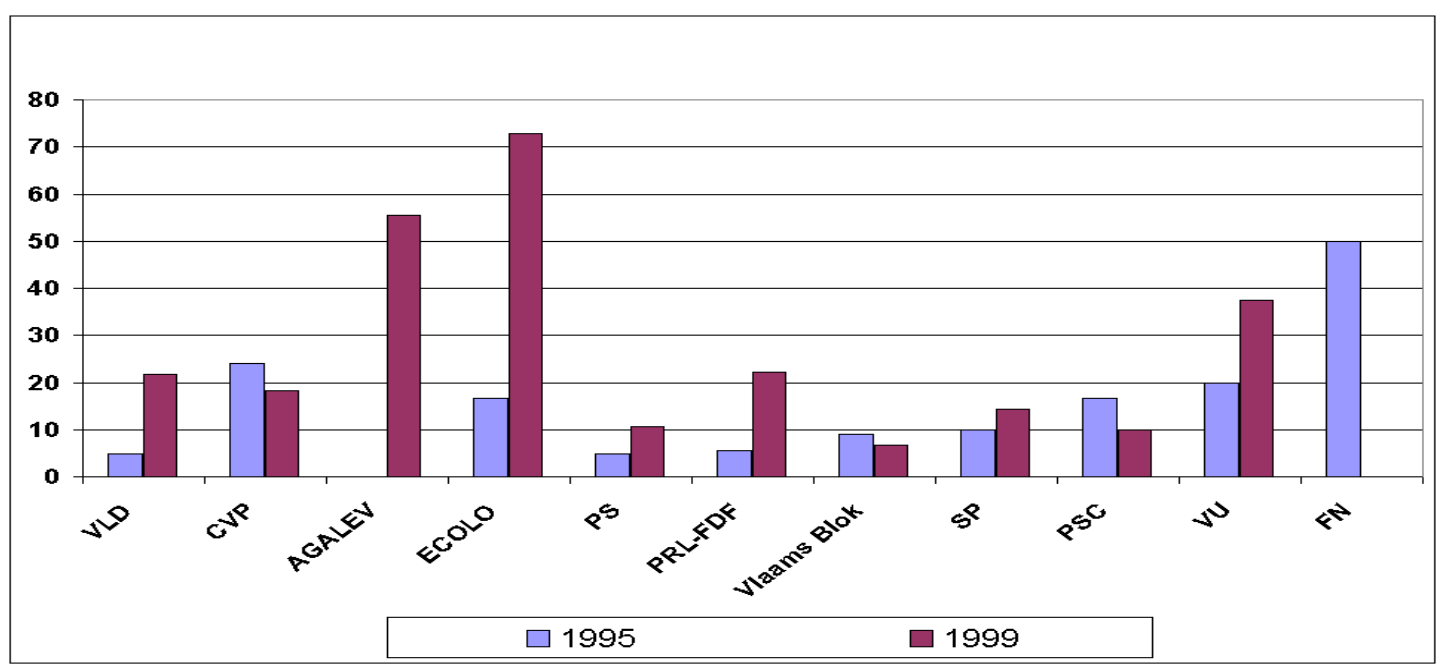

A Figura 7 mostra, porém, que não é este o caso. Enquanto partidos como VLD, Agalev, Ecolo, PS, PRL-FDF, SP e VU aumentaram a proporção de mulheres eleitas, outros, como CVP, Vlaams Blok, PSC e FN, tiveram uma diminuição. É interessante observar que, com exceção do

\footnotetext{
${ }^{24}$ Os dados para 1995 foram extraídos do "Relevé Statistique de l"Activité Parlementaire", Troisième session de la 49 législature, Doc. 7/2 - 95/96. Os dados para 1999 foram tirados do"Relevé Statistique de l"Activité Parlementaire", Deuxième session de la $50^{\mathrm{e}}$ législature, Doc. 0007/001.
} 
Vlaams Blok, o segundo grupo de partidos perdeu assentos em 1999, em comparação com 1995.

\section{O número de homens e mulheres na composição efetiva}

Os partidos no governo devem substituir membros que foram designados para posições ministeriais. Isso explica, por exemplo, a diferença entre a porcentagem de mulheres eleitas pelo SP $(0)$ e a porcentagem real de mulheres desse partido na Câmara (14,30\%). O número de mulheres no governo aumentou de $11,76 \%$ em 1995 para 16,67\% em 1999.

A Figura 8 mostra as diferenças entre porcentagens de mulheres diretamente eleitas e a composição final da assembléia por partido depois do processo de substituições.

Figura 8. Diferenças entre eleitas e composição efetiva 1999

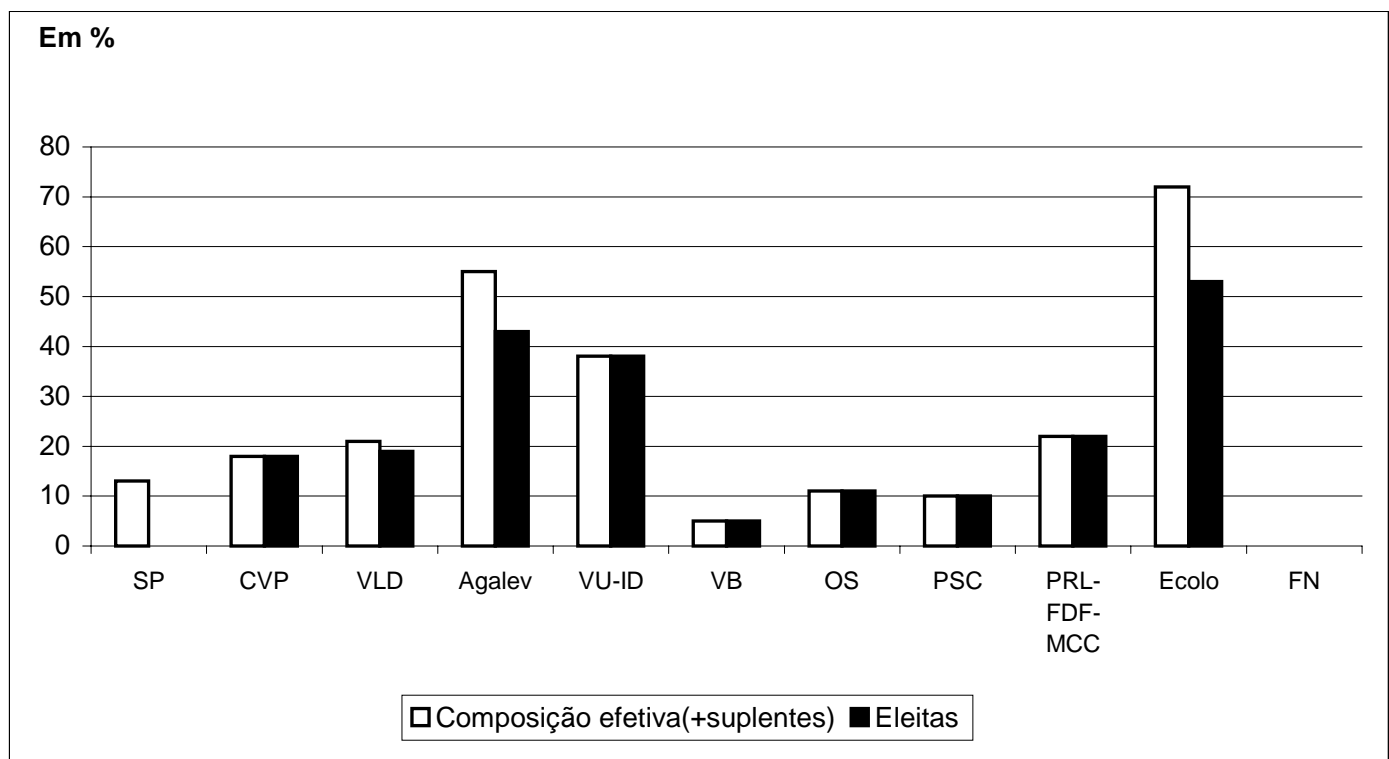

Obviamente, não houve nos partidos que não faziam parte do governo de 1999. Porém, isso também se aplica ao PS e PRL-FDF-MCC (partidos socialista e liberal francófonos), ainda que estivessem no governo, pois nenhum dos homens designado para o ministério foi substituído por uma mulher. A Tabela 4 mostra as porcentagens relativas por partido, isto é, as porcentagens de mulheres MPs que eram composta por suplentes. 
As cotas fazem diferença? Ações positivas no parlamento belga

Tabela 4. Porcentagem de mulheres diretamente eleitas e a composição final da assembléia para os partidos que formaram o governo de 1999

\begin{tabular}{|l|c|c||c||c||}
\cline { 2 - 5 } \multicolumn{1}{c|}{} & $\begin{array}{c}\text { Diretamente } \\
\text { eleitas }\end{array}$ & $\begin{array}{c}\text { Composição final } \\
\text { (i.e. diretamente } \\
\text { eleitas + suplentes) }\end{array}$ & Diferença & $\begin{array}{c}\text { Suplentes em } \\
\text { porcentagem da } \\
\text { composição final }\end{array}$ \\
\hline SP & 0 & 14.3 & 14.3 & 100 \\
\hline VLD & 17.4 & 21.7 & 4.3 & 19.82 \\
\hline Agalev & 44.4 & 55.5 & 11.1 & 20 \\
\hline Ecolo & 54.5 & 72.7 & 18.2 & 25.03 \\
\hline PS & 10.5 & 10.5 & 0 & 0 \\
\hline PRL-FDF-MCC & 22.2 & 22.2 & 0 & 0 \\
\hline \hline Total & $\mathbf{2 4 . 8 3}$ & $\mathbf{3 2 . 8 2}$ & $\mathbf{7 . 9 8}$ & $\mathbf{2 7 . 4 8}$ \\
\hline
\end{tabular}

O número de mulheres MPs é constituído exclusivamente por suplentes no SP. Nos outros três partidos, VLD, Agalev e Ecolo, as suplentes representam cerca de $20 \%$ a $25 \%$ do total de mulheres no Parlamento. Isso significa que, em média, por volta de $27 \%$ das mulheres MPs de 1999 eram inicialmente suplentes.

A análise das posições nas listas mostrou que, entre 1995 e 1999, não houve melhoria real em termos de oportunidades para as mulheres serem eleitas. Porém, uma vez que a composição sexual do Parlamento belga mudou consideravelmente entre as duas eleições, falta descobrir a causa dessa mudança. Desse modo, realizaram-se três análises regressivas para identificar qual dos fatores acima mencionados (posições elegíveis dadas às mulheres, perdas e ganhos do partido entre duas eleições consecutivas, o fato de que façam parte ou não do governo, as ações dos partidos para melhorar o equilíbrio entre os sexos e finalmente, a lei sobre cotas) tem um impacto maior sobre o número de mulheres MPs quando os outros são mantidos sob controle. As unidades de análise são as listas dos partidos.

O primeiro modelo baseia-se na eleição de 1995, o segundo, na eleição de 1999 e o terceiro inclui ambas as eleições em um modelo geral. O último modelo é interessante, pois mostra uma aproximação do efeito de cotas. A variável chamada "lei de cotas" foi codificada como dicotômica, onde (0) é usado para aqueles casos anteriores à lei sobre cotas e (1) para os posteriores à entrada em vigor da lei. Outra variável é a de "partidos que formam o governo", que mede o efeito das substituições sobre o equilíbrio sexual das assembléias. 
Tabela 5. Modelo de regressão prevendo o número de mulheres MPs em 1995 e 1999 (coeficientes padronizados)

\begin{tabular}{|c|c|c|c|}
\hline & \multicolumn{3}{|c|}{$\begin{array}{c}\text { Variável prevista: número efetivo de } \\
\text { mulheres no Parlamento }\end{array}$} \\
\hline & $\begin{array}{c}1995 \\
\mathrm{~N}=115 \\
\end{array}$ & $\begin{array}{c}1999 \\
\mathrm{~N}=116 \\
\end{array}$ & \begin{tabular}{|c|} 
Modelo geral 95-99 \\
$\mathrm{N}=231$ \\
\end{tabular} \\
\hline (Constante) & -0.043 & -0.053 & $-0.188^{*}$ \\
\hline Número de mulheres em posições elegíveis & $0.659^{* *}$ & $0.492^{* *}$ & $0.536^{* *}$ \\
\hline Número de mulheres no topo da lista & 0.104 & 0.090 & $0.132^{*}$ \\
\hline $\begin{array}{l}\text { Diferença entre o número de assentos (91-95 e } \\
95-99 \text { respectivamente) }\end{array}$ & $-0.388^{* *}$ & $-0.582^{* *}$ & $-0.466^{\star *}$ \\
\hline $\begin{array}{l}\text { Partidos que formam o governo ( } 0 \text { =fora do gov. } \\
1=\text { no gov.) }\end{array}$ & 0.164 & $0.226^{\star \star}$ & $0.231^{* *}$ \\
\hline $\begin{array}{l}\text { Ações dos partidos para equilíbrio de gêneros } \\
(0=\text { sem } 1=\text { com })\end{array}$ & 0.025 & 0.134 & 0.047 \\
\hline Lei de cotas ( $0=$ antes $1=$ depois) & & & $0.108^{*}$ \\
\hline R quadrado ajustado & $0.423^{* *}$ & $0.454^{\star *}$ & $0.420^{* *}$ \\
\hline
\end{tabular}

Como mostra o modelo geral, o efeito mais significativo é o do número de mulheres em posições elegíveis, seguido pelos ganhos e perdas dos partidos que compõem o governo em termos de assentos entre duas eleições consecutivas. 0 efeito das substituições nos partidos do governo vem em terceiro lugar, logo acima do número de mulheres no topo da lista. O efeito das substituições é maior em 1999 do que em 1995, o que significa que, em termos relativos, a "coalizão arcoíris" (Ecolo, Agalev, PS, SP, PRL-FDF-MCC, VLD) substituiu mais homens, que haviam sido diretamente eleitos, por mulheres do que a coalizão de 1995 (Ps, SP, PSC, CVP). Uma forma simples de medir o efeito da legislação sobre cotas na composição sexual da assembléia de 1999, como já foi mencionado, é computar uma variável com duas categorias: antes e depois da vigência da lei. O coeficiente de .108 mostra que o efeito da lei, embora pequeno, foi significativo e positivo. Analisando os modelos para 1995 e 1999, é interessante notar que o fator mais forte para prever o equilíbrio sexual do Parlamento em 1995 ainda é o número de mulheres em posições elegíveis, mas não ocorre o mesmo em 1999. As diferenças dos partidos em termos de assentos entre 1995 e 1999 se tornaram o fator mais 
As cotas fazem diferença? Ações positivas no parlamento belga

forte, seguido pelo número de mulheres em posições elegíveis.

\section{Conclusões}

Neste artigo, levantou-se a questão sobre os limites em relação ao tipo de cota implementada na Bélgica. Antes de fazer uma avaliação final, é preciso resumir vários elementos: (1) os partidos políticos belgas desempenham um papel decisivo no processo de escolha, determinando em última instância quem será eleito (Deschouwer, De Winter e Della Porta, 1996); (2) o atual sistema de cotas permite que os partidos decidam a posição dos candidatos, o que tem importância fundamental pois, quanto mais alta a posição do candidato na lista, maiores suas chances de se eleger (ordre utile); (3) ao depositar seu voto, o eleitor tem duas alternativas possíveis: escolher a lista toda ou optar por candidatos individuais. Porém, o assim chamado "efeito de devolução" dá prioridade aos candidatos

situados no topo da lista. Assim, mesmo que um candidato tenha mais votos pessoais, o sistema privilegia as posições mais altas na lista. Dessas três observações é fácil deduzir teoricamente que o efeito das cotas, baseado exclusivamente na quantidade, em vez de na posição (fator fundamental no sistema eleitoral belga), depende em larga medida da vontade dos partidos de incluir mais mulheres na sua representação parlamentar.

Concentrando-nos agora nos dois principais mecanismos para obter a representatividade (paridade e cotas), os argumentos em favor da primeira estão mais bem posicionados do que os em favor das cotas no que se refere à crítica freqüente do: "se dermos cotas para as mulheres, onde vamos parar (jovens, imigrantes etc)?" Pois há algo específico no sexo que as outras características sociodemográficas não possuem. A humanidade foi dividida em dois lados, um masculino, outro feminino: essa característica é compartilhada por todas as sociedades e, portanto, é um componente essencial de todas elas. De um ponto de vista puramente pragmático, na medida em que as cotas são restritas a um determinado limite, depois que os partidos o atingirem, há o risco de as mulheres jamais ultrapassarem esse limite. Isso é algo que a idéia de paridade pode contornar.

Por mais razoáveis que possam parecer, os pressupostos teóricos são uma coisa e a prova empírica é outra. O objetivo deste artigo é comparar oportunidades dadas a candidatos do sexo masculino e feminino no processo eleitoral. Isso permite determinar qual parte da atual composição sexual da Câmara de Deputados belga se deve à legislação sobre cotas e qual se deve a outros fatores. Depois de examinar esse processo, das listas de candidatos à composição final da Câmara, é possível distinguir dois tipos de implementação das cotas entre os partidos políticos. Uma pode ser chamada de "abordagem minimalista", isto é, cumprir as exigências da lei pondo $1 / 3$ de mulheres nas listas de candidatos, mas 
não colocá-las em posições elegíveis. O outro tipo de implementação é a "abordagem maximalista", isto é, uma estratégia em que homens e mulheres Figuram em termos iguais nas listas. As abordagens estão evidentemente relacionadas com as posições dos partidos com respeito à lei.

A resposta à pergunta do título deste artigo é "sim, mas...". Indicamos as diferenças entre a porcentagem de candidatas nas listas (39\%) e o número de mulheres eleitas $(21 \%)$ e a composição efetiva das assembléias $(23,3 \%$ de mulheres). Uma vez que os partidos devem decidir sobre o posicionamento nas listas, não é estranho encontrar diferenças entre as porcentagens de mulheres eleitas e a de mulheres no Parlamento. Um exame das listas de candidatos em termos do que é chamado de "ordem útil" (isto é, o número de assentos que os partidos ganharam na eleição anterior e que esperam pelo menos manter na próxima) mostra que o número de mulheres em posições elegíveis não mudou muito de 1995 (antes das cotas) para 1999. No entanto, o número de mulheres no Parlamento quase dobrou (de $12 \%$ para $23 \%$ ). O que provocou essa diferença, visto que não foi a lei sobre cotas? A regressão mostrou que em 1999, o efeito maior se deveu ao fato de que certos partidos ganharam assentos na eleição daquele ano. Porém, a lei sobre cotas também teve um impacto, ainda que pequeno. Os ganhos de certos partidos não somente foram mais importantes, como também o número de mulheres em posições elegíveis, o efeito das substituições e o número de mulheres no topo das listas. Desse modo, ficamos com a impressão de que o equilíbrio entre os sexos na Câmara Federal de Deputados da Bélgica é frágil e instável. Se não forem criados mecanismos suplementares, esse equilíbrio pode ser facilmente rompido. E como mostramos ainda, isso poderá também ser creditado facilmente à vontade do eleitorado. De acordo com a opinião pública, uma grande maioria dos eleitores votou tanto em homens como em mulheres. Porém, o número de mulheres no Parlamento ainda é de $23 \%$. Com efeito, pode-se pensar que existe um hiato entre o que os partidos oferecem e o que os eleitores pedem.

A questão da representação feminina continua na agenda do sistema político belga. Em 1998, J oos Wauters e Martine Schüttringer sugeriram que se aplicasse a paridade na Bélgica, em vez de $\operatorname{cotas}^{25}$. Em 24 de janeiro de 2002, a Câmara Federal de Deputados decidiu que o Artigo 10 da Constituição deveria ser emendado e estipular que "a igualdade entre mulheres e homens é garantida" ${ }^{26}$. O Senado adotara anteriormente, por unanimidade, a mesma emenda. Também foi adicionado à Constituição (Artigo 11b) que homens e mulheres têm garantia, por lei, de acesso igual a postos públicos e eleitos e que ambos os sexos devem estar representados em todos os órgãos executivos. Em concordância com essas mudanças, espera-se agora que a vice-primeira ministra, Mme. Onkelinx, proponha

\footnotetext{
${ }^{25}$ Doc. 1731/1, Câmara de Deputados belga, 10 de setembro de 1998.

26 "L'égalité entre des femmes et des hommes est garantie". Artigo 10.
} 
que o princípio da paridade substitua o princípio das cotas e que mulheres e homens sejam colocados nas listas como candidatos aos dois postos mais altos. Outras alternativas foram sugeridas. Uma proposta para modificar a Lei Eleitoral e eliminar o "efeito de devolução" e a distinção entre efetivos e suplentes nas listas foi apresentada no início de 2000 pelos deputados Luc Pâque, J oëlle Milquet e J eanPol Poncelet ${ }^{27}$. Em 26 de junho de 2000, a Câmara aprovou uma lei que busca reduzir o efeito devolutivo em $50 \%$ nas eleições para os conselhos provinciais e comunais, bem como para o Parlamento Europeu, além de suprimir a distinção entre candidatos efetivos e suplentes ${ }^{28}$. Em 27 de dezembro, a lei foi aprovada para ambas as Câmaras Federais e para as eleições do Conselho da Comunidade Germânica $^{29}$. A reforma pretende tornar o sistema eleitoral mais transparente, simplificando-o e diminuindo o papel dos partidos políticos na seleção das pessoas eleitas ${ }^{30}$.

Concluindo, se o objetivo de medidas como cotas e paridade é alcançar uma estrutura equilibrada em termos de gênero na assembléia legislativa, elas precisam ser complementadas com regulações sobre a posição de mulheres e homens nas listas partidárias. Foi feita também uma proposta de introdução desse tipo de legislação na Bélgica em $2005^{31}$. Independente da posição filosófica com relação a cotas e paridade, essas ações positivas deveriam ser combinadas com, por exemplo, a "prática do zíper", isto é, a alternância de sexos na composição das listas. Essa prática foi aplicada com sucesso pelos partidos verdes.

As cotas poderiam fazer diferença se não tratassem apenas da quantidade, mas também da ordem dos candidatos nas listas. Ainda que o número seja importante, devido ao simbolismo de criar um equilíbrio artificial entre os sexos, a base da mudança continua nas esferas social e cultural. Se o principal objetivo é uma verdadeira igualdade de oportunidades, é preciso implementar ao mesmo tempo ações estruturais para educar ou mudar as mentalidades.

\footnotetext{
27 "Proposition de loi modifiant le code électoral, em vue de supprimer l'effet dévolutif de la case de tête et les listas des suppléants aux élections législatives". Ver Documentos da Câmara de Deputados belga (9/2/2000): Doc 436/1; Doc. 434/1; Doc. 435/1.

Documentos da Câmara de Deputados (10/9/1998): Doc. 1731/1; Doc. 1732/1; Doc. 1732/1; Doc. 1734/1; Doc. 1735/1; Doc. 1736/1; Doc. 1737/1; Doc. 1738/1.

${ }^{28}$ Lei publicada no Moniteur Belge de 14 de julho de 2000.

${ }^{29}$ Publicado no Moniteur Belge em 24 de janeiro de 2001.

${ }^{30}$ Ver Doc.434/1, Câmara de Deputados belga, de 9 de fevereiro de 2000. Ver também Doc. 1734/1, 15 de setembro de 1998.

${ }^{31}$ A "paridade dupla", tal como sugerida nas Minutas da Reunião de Gabinete de 19 de maio de 2000, foi concebida como uma fórmula progressiva e provisória, cujo cronograma seria o seguinte: a partir de 2001, as listas partidárias deveriam seguir o princípio de paridade (50-50). Para as eleições legislativas de 2003 e para as eleições regionais e européias de 2004, pelo menos uma mulher (ou um homem) deveria estar entre os três primeiros candidatos em cada lista. Por fim, a partir de 2005, deveria ser respeitada a alternância de sexos nos dois primeiros lugares das listas.
} 


\section{BIBLIOGRAFIA}

CAUL, M. 1999. "Women's Representation in Parliament. The Role of Political Parties", Party Politics, 5(1) 79-98.

CELIS, K., et al..1998. «Femme et politique en Belgique ». Sophia, 16, dezembro.

CHAMPAGNE, P. 1990. Faire l'opinion. Le nouveau jeu politique, Paris, Ed. Minuit.

COENEN, M.-T. 1998. "Les femmes font-elles partie de la nation?", in H. PEEMANS-POULLET (ed.) La Démocratie à l'épreuve du Féminisme. Bruxelas, Université des Femmes, pp. 19-47.

DAHLERUP, D. 1988. "From a Small to a Large Minority: Women in Scandinavian Politics". Scandinavian Political Studies, 11(4).

DESCHOUWER, K., DE WINTER, L. e DELLA PORTA, D. 1996. "Partitocracies between crises and reforms: The cases of Italy and Belgium". Res Publica, 38(2).

DUVERGER, M. 1955. La participation des femmes à la vie politique, Paris, Unesco.

GUBIN, E.1998. "Le suffrage féminin en Belgique (1830-1921). Arguments et enjeux". in H. PEEMANS-POULLET (ed.) La Démocratie à l'épreuve du Féminisme. Bruxelas, Université des Femmes, pp. 49-75.

GUBIN, E. e VAN MOLLE, 1998. L. Femmes et politique en Belgique. Bruxelas, Editions Racine.

HELD, D. 1997. Models of Democracy. Polity Press, Cambridge.

KAISER, P. 1999. "Party Incentives and Women's Parliamentary Participation: A Comparative Study of Six OECD Countries". Trabalho apresentado na Reunião Anual da American Political Science Association, setembro.

MANIN, B. 1995. Principes du gouvernement représentatif, Paris, Flammarion.

MARQUES-PEREIRA, B. 1998. «La Parité: Les Termes Du Débat », IN H. PEEMANS-POULLET (ed.) La Démocratie à l'épreuve du Féminisme. Bruxelas, Université des Femmes, pp. 175-191.

MATEO DIAZ, M. e AISH, A.-M. 1999. «Femmes et démocratie. Les attitudes des électeurs wallons à l'égard des femmes en politique ", in A.-P. FROGNIER e A.-M. AISH (eds.), Des élections en trompe-l'œil. Bruxelas, De Boeck, pp. 121-159.

NORRIS, P. 2000. "Breaking the Barriers: Positive Discrimination Policies for Women", in J. KLAUSEN, e C.S. MAIER, Has Liberalism Failed Women? Parity, Quotas and Political Representation. Nova York, St Martin's Press.

NORRIS, P. e LOVENDUSKI, J. 1995. Political Recruitment. Gender, Race and Class in the British Parliament. Cambridge, Cambridge University Press. 
UNION INTERPARLEMENTAIRE. 1992. Les Femmes et le Pouvoir Politique. Enquête menée auprès des 150 Parlements nationaux existant au 31 octobre 1991, Genebra, Rapports et Documents $N^{\circ} 19$.

UNION INTERPARLEMENTAIRE. 1995. Les Femmes dans les Parlements 1945-1995 Etude statistique mondiale, Genebra.

VERDUSSEN, M. 1998. «La participation des femmes aux élections en Belgique ». Revue française de Droit constitutionnel, 36.

constitutionnel, 1.

1999. "La parité sexuelle sur les listes de candidat(e)s ». Revue belge de Droit

VERZELE, V. e JOLY, C. 1999. "La représentation des femmes en politique après les élections du 13 juin 1999. Evaluation de l'application de la loi Smet-Tobback». Courrier Hebdomadaire du CRISP, 1662-63. 